\title{
Klinefelter syndrome, cardiovascular system, and thromboembolic disease: review of literature and clinical perspectives
}

\author{
Andrea Salzano', Michele Arcopinto², Alberto M Marra3, Emanuele Bobbio', \\ Daniela Esposito4, Giacomo Accardo4, Francesco Giallauria1, Eduardo Bossone5, \\ Carlo Vigorito', Andrea Lenzi ${ }^{6}$, Daniela Pasquali ${ }^{4}$, Andrea M Isidori ${ }^{6}$ and \\ Antonio Cittadini ${ }^{1}$
}

${ }^{1}$ Department of Translational Medical Sciences, University "Federico II", Naples, Italy, 2Department of Cardiac Surgery, IRCCS Policlinico San Donato, Milan, Italy, ${ }^{3}$ IRCSS SDN, Via E. Gianturco 113, Naples, Italy, ${ }^{4}$ Department of Cardiothoracic and Respiratory Science, Endocrinology Unit, Second University of Naples, Italy, "Department of Cardiology and Cardiac Surgery, University Hospital "Scuola Medica Salernitana", Salerno, Italy and ${ }^{6}$ Department of Experimental Medicine, Sapienza University of Rome, Rome, Italy

\author{
Correspondence \\ should be addressed \\ to Antonio Cittadini \\ Email \\ antonio.cittadini@unina.it
}

\begin{abstract}
Klinefelter syndrome (KS) is the most frequently occurring sex chromosomal aberration in males, with an incidence of about 1 in 500-700 newborns. Data acquired from large registry-based studies revealed an increase in mortality rates among KS patients when compared with mortality rates among the general population. Among all causes of death, metabolic, cardiovascular, and hemostatic complication seem to play a pivotal role. KS is associated, as are other chromosomal pathologies and genetic diseases, with cardiac congenital anomalies that contribute to the increase in mortality. The aim of the current study was to systematically review the relationships between KS and the cardiovascular system and hemostatic balance. In summary, patients with KS display an increased cardiovascular risk profile, characterized by increased prevalence of metabolic abnormalities including Diabetes mellitus (DM), dyslipidemia, and alterations in biomarkers of cardiovascular disease. KS does not, however, appear to be associated with arterial hypertension. Moreover, KS patients are characterized by subclinical abnormalities in left ventricular (LV) systolic and diastolic function and endothelial function, which, when associated with chronotropic incompetence may led to reduced cardiopulmonary performance. KS patients appear to be at a higher risk for cardiovascular disease, attributing to an increased risk of thromboembolic events with a high prevalence of recurrent venous ulcers, venous insufficiency, recurrent venous and arterial thromboembolism with higher risk of deep venous thrombosis or pulmonary embolism. It appears that cardiovascular involvement in KS is mainly due to chromosomal abnormalities rather than solely on low serum testosterone levels. On the basis of evidence acquisition and authors' own experience, a flowchart addressing the management of cardiovascular function and prognosis of KS patients has been developed for clinical use.

European Journal of Endocrinology (2016) 175, R27-R40
\end{abstract}

\section{Introduction}

Klinefelter syndrome (KS) is the most common abnormality of sex chromosomes (47, XXY or a mosaic karyotype) and is characterized by hypergonadotropic hypogonadism (1). Data indicate the incidence of KS to be as high as 1/660 of newborns $(2,3)$. Despite its first mention being 70 years (c) 2016 European Society of Endocrinology Printed in Great Britain ago (1), little data are available with regard to the morbidity and mortality of KS. Data from recent large registry-based studies $(4,5,6,7,8)$ indicated an increase in mortality in KS patients when compared with the general population. Interestingly, mortality was specifically increased by 
concomitant cardiovascular diseases: KS was associated with a significant increase in mortality risk by $40 \%$ (Hazard ratio (HR) for all-cause mortality=1.40; HR cardiovascular mortality =1.41). However, it should be acknowledged that these studies were only based on those cases of KS that have been clinically diagnosed; thus, undiagnosed KS cases may underestimate cardiac mortality.

Indeed, several reports suggest that $\mathrm{KS}$ is associated with a higher cardiovascular risk profile, subclinical cardiovascular abnormalities, and impaired exercise performance. Surprisingly, it appears that KS patients are at lower risk for ischemic heart disease, although other cardiovascular events are more common in patients with KS (7).

The aim of this work was to systematically review the relationships among KS and the cardiovascular system, and alterations of hemostasis and thrombosis. We searched Medline for articles published in any language until July, 28 2015, with the following keywords: 'Klinefelter syndrome', 'cardiovascular', 'heart', 'congenital abnormalities', 'diabetes mellitus', 'metabolic syndrome', 'hemostasis and thrombosis', 'platelet hyperaggregability'. Accordingly, we identified 90 articles.

\section{Cardiovascular risk profile in Klinefelter syndrome}

The increased cardiovascular mortality observed in KS should, in theory, point to a higher prevalence of cardiometabolic risk factors in these subjects. However, little information is available with regard to the prevalence of traditional cardiovascular risk factors in $\mathrm{KS}$, or to the presence of subclinical cardiovascular involvement.

\section{Metabolic syndrome}

Few works, aimed at investigating the prevalence of metabolic syndrome (MS) in subjects with KS, showed a high prevalence of this preclinical condition in $\mathrm{KS}$ (Table 1). In particular, Bojesen et al. (9) compared $70 \mathrm{KS}$ subjects with a control population and showed a striking increase in MS prevalence in KS (42\% in KS vs $10 \%$ in controls).

Ishikawa et al. (10) found a prevalence of 34\% of MS in $60 \mathrm{KS}$ patients, confirming previous observations. Recently, Pasquali et al. (11) have shown a prevalence of $50 \%$ in $69 \mathrm{KS}$ subjects, compared with 10\% in the control group, and a MS prevalence of $28 \%$ in a population of non-KS, testosterone-treated, hypogonadotropic hypogonadic subjects. Moreover, despite the limitations in terms of study size, in prepubertal adolescents with KS, Bardsley et al. (12) showed an increased prevalence of MS (about $7 \%)$ compared with healthy age-matched subjects. Even for a similar body mass index (BMI), infants and adolescents (4-18 year) with KS have a higher level of body fat, and especially of truncal fat (BFtr) with a reduction in lean mass, than the general population (13). Bojesen et al. (9) found that the strongest predictor of MS was adiposity, especially BFtr. In a multivariate analysis, BFtr was the independent variable with the most significant impact on both metabolic syndrome and measures of insulin sensitivity. Interestingly, when controlling for BFtr, the impact of hypogonadism on the presence of the MS or not and on insulin sensitivity disappeared, supporting the hypothesis that measures of insulin resistance, hepatic glucose output, and insulin secretion were not dependent on sex hormone levels after controlling for upper body obesity. The authors (14) suggested that a vicious cycle might ensue in KS, with hypogonadism influencing body composition, causing an increase in body fat (especially intra-abdominal fat), subsequently deteriorating carbohydrate metabolism, causing insulin resistance which further aggravates the hypogonadism via a direct effect on Leydig cell production of residual testosterone.

Despite the relatively small sample size and the nonmechanistic nature of the studies, these data support the hypothesis that the increased visceral fat precedes the hypogonadism and that MS may be associated with KS independent of the hypogonadism. In addition, testosterone therapy does not appear to change the prevalence of MS $(9,11)$, nor improve the indices of insulin resistance (IR). Interestingly, MS is closely associated with a low-grade chronic inflammatory status characterized by abnormal cytokine production, which activates a network of inflammatory signaling pathways. Overproduction of CCL2 is associated with insulin resistance. Rotondi et al. (15) showed significantly higher serum levels of CCL2 in KS compared with controls. On the contrary, no significant differences in serum CXCL10 and adiponectin were observed between the two groups. In vitro studies have shown that testosterone exerts a powerful anti-inflammatory effect, as assessed by its ability to reduce the secretion of several cytokines and chemokines including CCL2. However, acute testosterone deprivation in healthy men leads to an increase in serum CCL2 levels, which is not reversed by restoration of physiological circulating concentrations of testosterone. Furthermore, the differences in the response to testosterone replacement therapy in KS could be dependent upon androgen receptor polymorphism $(16,17,18)$. These results suggest that, in addition to hormonal factors, a genetic predisposition, possibly 
Table 1 Characterization and effects of testosterone replacement therapy on cardiovascular risk factors in Klinefelter syndrome.

References

(12)

Diabetes mellitus

(20)

(21)

(23)

\section{Dyslipidemia}

(9)

(29)

(12)

Hormones and biomarkers

(9)

(9)

(11)

Rev, review of literature.

mediated through macrophage infiltration into adipose tissue, is involved in the development of MS in KS (15).

\section{Diabetes}

Since Mirouze and coworkers coined the term "Prediabetes in KS" (19) in 1966, most studies reported an increased incidence of diabetes mellitus (DM) in KS $(5,7,19,20,21,22,23,24,25,26)$. In large registrybased studies, Bojesen (5) and Swerdlow (7), taking into account cause-specific mortality ratios, showed a relative risk (RR) of DM of 1.64 and 7.07, respectively. Furthermore, KS and DM are associated with increased mortality (7). Notably, replacement testosterone therapy does not seem to affect the prevalence and incidence of DM in KS (Table 1). Unfortunately, the data on testosterone replacement in KS are extremely heterogeneous in modality, length of treatment, and preparation used. Based on current evidence, it cannot be excluded that a lack of reversibility is related to inadequate regimen schemes, such as those producing repeated peaks and nadirs, as with some old formulation of injectable testosterone esters, suboptimal dosing secondary to a low absorption, or an excessive delay in commencing replacement therapy leading to irreversible changes. The most recent meta-analysis on the cardiovascular safety of testosterone replacement in the general population (27) failed to identify a difference in the events associated with the type of preparations used. However, society guidelines suggest transdermal preparations or long-acting injectable $\mathrm{T}$ undecanoate to reduce the risk of excessive hematocrit increase $(28,29)$. 


\section{Dyslipidemia}

Dyslipidemia has been reported in KS, consisting in high levels of total and low-density lipoprotein (LDL) cholesterol as well as tryglycerides (30). Bojesen and coworkers, comparing testosterone-treated and untreated KS, showed lower LDL and total cholesterol levels in the Testosterone-treated group (9). However, these data were not confirmed by Pasquali et al. (11) (Table 1).

\section{C-reactive protein}

Another biomarker measured in KS patients is C-reactive protein (CRP), a well-known inflammatory protein that predicts cardiovascular outcome (31). In KS, CRP levels are increased at baseline $(9,32)$ and significantly reduced in the Testosterone-treated group (9).

\section{Endothelial progenitor cells}

It has been demonstrated that reduced circulating endothelial progenitor cells (EPCs) are independent predictors of atherosclerotic progression and morbidity/ mortality due to cardiovascular disease (33). Specifically, the concentration and the migratory activity of EPCs inversely correlates with the risk factors for coronary artery disease $(34,35)$. Di Mambro and coworkers demonstrated a reduced number of EPCs in 68 KS subjects compared with age-matched controls and hypogonadal patients, independent of testosterone levels and of the presence/ absence of other cardiovascular risk factors $(36,37)$. Interestingly, testosterone replacement therapy exerted no effect on EPCs number, differently from what was observed in normal, testosterone-treated subjects (38). Congruent with this observation, Ru et al. (39) showed that in KS subjects testosterone levels were not correlated with the number of EPCs (Table 1). Given the growing interest of the scientific community in the study of EPCs $(40,41,42,43,44)$, further studies are needed to explain the relationship between EPCs and KS.

\section{Leptin and adiponectin}

An intriguing biomarker studied in KS is leptin, which provides an afferent signal in a negative-feedback loop regulating the size of adipose tissue mass. Leptin is produced by adipocytes, and it is directly related to body fat mass (45). In KS, increased levels of leptin are demonstrated (9) with no difference in the Testosteronetreated group (9).
Interestingly, it seems that patients with KS are somehow protected by arterial hypertension (AH). A possible explanation for this finding may involve adiponectin physiology. Low levels of this hormone are indeed associated with systemic arterial hypertension, DM, and coronary artery disease $(46,47,48)$. Although decreased levels of adiponectin in the general population characterize MS, KS subjects with MS display normal levels of this adiponectin (9) and this may prevent the development of $\mathrm{AH}$ in KS. Notably, in KS hypogonadism is relative rather than absolute. The nonsuppressed level of adiponectin may therefore be the result of the opposing effect of (subnormal) testosterone levels and obesity.

Taken together, patients with KS display an impaired cardiovascular risk profile characterized by increased prevalence of metabolic abnormalities including DM, dyslipidemia, and alteration in biomarkers of cardiovascular disease. However, KS does not appear to be associated with arterial hypertension.

\section{Structural and functional cardiovascular abnormalities in Klinefelter syndrome}

Resting EKG characteristics in KS have been recently studied by Jørgensen et al. (49). These authors found a shorter QTc-interval in KS compared with controls. However, corrected QT interval (QTc) was shortest among testosterone-treated males with KS, while untreated and hypogonadal KS had intervals comparable to controls. No mutations of genes related to short QT syndrome were found. These results suggest that genes on the $\mathrm{X}$ chromosome could be involved in the regulation of the QTc-interval and that testosterone treatment significantly modulates this mechanism. Recently, EXAKT trial suggests that cardiac rhythmogenic stability, expressed as 12-lead EKG QTc time, was markedly altered in KS patients (50). In this cross-sectional prospective project involving $132 \mathrm{KS}$ patients, authors demonstrated that QTC time was significantly shorter in those patients showing higher levels of differentially expressed genes (DEGs). Pathologically short QTc times ( $<370 \mathrm{~ms})$ were observed in 11 KS patients but in none of the controls. In particular, the effect was even more pronounced in those men with a paternal origin of the supernumerary $\mathrm{X}$ chromosome. Moreover, serum testosterone levels were not associated with QTc times (50). Karagoz et al. (51) reported a case of a sinus node dysfunction requiring permanent pacemaker implantation in a 22-year-old man with KS.

Few pioneering reports aimed at assessing left ventricular (LV) structure in KS were performed by Fricke et al. 
$(52,53)$. In these studies, a prevalence of $55 \%$ of mitral valve prolapse (MVP) was found in 22 patients with KS. On the contrary, despite two case reports confirmed the presence of mitral valve prolapse in KS $(54,55)$, two more recent large studies $(11,14)$ (25 and 69 patients respectively) did not confirm this finding. Andersen et al. (14) found only subclinical alteration of the LV systolic function (reduction in LV strain and strain rate) with a normal LV fraction in $25 \mathrm{KS}$ subjects. A subgroup analysis showed that only KS subjects with MS displayed such alteration in which no differences between T-treated and untreated patients were found (median duration therapy of 9.5 years). The correlation between strain/Doppler indices of systolic function and fasting triglyceride and truncal body fat led the authors to speculate that myocardial systolic function impairment was strictly related with MS rather than to KS itself. To support this hypothesis, this pattern is commonly found in patients with obesity and MS, and appears linked to insulin resistance $(56,57)$.

Pasquali et al. (11) showed no significant difference in LV structure in 69 KS patients compared with controls, nor evidence of MVP. In the same study, no significant alterations of LV systolic function were reported, although strain analysis was not performed (11). With regard to diastolic function, Andersen et al. (14) showed a $20 \%$ prevalence $(5 / 25)$ of diastolic dysfunction in KS patients. In particular, in a multiple regression analyses considering the measurements of mitral inflow, peaks $\mathrm{E}$ (early diastolic filling) and A (late diastolic filling), velocities ratio (E/A) (but not $\mathrm{E}$ and early diastolic annular velocity ratio (E/E)) significantly correlated with truncal body fat. Accordingly, Pasquali et al. (11) reported a significant prolongation of isovolumic relaxation time and mitral deceleration time, decreased E/A ratio, and pulmonary vein velocities consistent with mild diastolic dysfunction, with no differences observed between treated and untreated KS patients. Notably, patients with secondary hypogonadism on testosterone therapy did not display normal cardiovascular parameters (Table 2).

With regard to cardiopulmonary exercise performance, Bojesen et al. (9) showed a reduced peak oxygen uptake $\left(\mathrm{VO}_{2}\right.$ max) in $70 \mathrm{KS}$ patients, with no difference between treated and untreated subjects. In a multivariate analysis, $\mathrm{VO}_{2} \max$ was negatively correlated to body truncal fat, diagnosis of KS, $17^{\circledR}$-estradiol, and age, but positively to the intermuscolar adipose tissue-free skeletal mass. KS per se was the strongest (negative) predictor of $\mathrm{VO}_{2}$ max, followed by skeletal muscular mass. Pasquali et al. $(11,58)$ observed an impaired cardiopulmonary performance and exercise capacity in KS reporting a marked reduction in $\mathrm{VO} 2$ peak and workload both at peak exercise ( $-34 \%$ vs controls) and anaerobic threshold
( $-24 \%$ vs control) compared with controls. Interestingly, KS displayed a remarkably increased prevalence of chronotropic incompetence (CI) defined as a lower proportion of predicted maximum heart rate (HRa) (78 vs $91 \%, P<0.05)$ and a lower increase in HRa from baseline to exercise peak (74 vs $91 \mathrm{bpm}, P<0.01$ ) (Table 2). CI is a common finding in several cardiovascular diseases (58), produces exercise intolerance that greatly impact on quality of life, and is an independent predictor of major adverse cardiovascular events and overall mortality in asymptomatic population $(59,60)$.

Several studies reported the predictive role of carotid intima media thickness (cIMT), a surrogate marker of atherosclerotic disease, on future cardiovascular event. Reduced flow mediated dilation (FMD), briefly described as endothelium-dependent vasodilation assessed by measuring the maximum increase in brachial artery diameter during reactive hyperemia created by the inflation of a cuff ( $250 \mathrm{mmHg}$ for $5 \mathrm{~min}$ ) placed on the right arm, has been considered as a predictor of cardiovascular disease, although its value for risk stratification is still debatable $(61,62)$. Foresta et al. (63), comparing $92 \mathrm{KS}$ subjects with controls, showed reduced diameters of brachial, common carotid, common femoral arteries, and abdominal aorta arteries. No difference between KS patients and control with regard to cIMT and FMD were found. On the other hand, KS patients enrolled in the study by Pasquali et al. (11) exhibited a significant increase in cIMT (Table 2). It should be highlighted that difference in cIMT is not clinically relevant, because in both studies, it was lower than $0.9 \mathrm{~mm}$ (64).

Recent data have suggested that the vasculature of the testis might be altered in animal models of KS (65). Interestingly, an alteration in vascular density and flow is observed early in KS boys during pubertal development (66) and it has been correlated with progressive luteinizing hormone (LH) rise. Little is known on the microvascular status of other tissues; however, the increased frequency of autoimmune disorders in KS (67) suggests that other than hormonal mechanisms could also be involved in altering tissue perfusion.

In spite of the fact that KS is the second most frequently occurring chromosome disease and that almost $15-20 \%$ of all congenital cardiovascular diseases (CCDs) are related to chromosomal disease $(68,69)$, few data are available addressing the prevalence of congenital heart diseases in this population. Compared with the general population, Bojesen et al. (4) showed a significant increase in CCD risk (HR 4.71) in KS. Among $3550 \mathrm{KS}$ subjects, Swerdlow et al. (7) reported that CCD was the specific cause of mortality in five patients (Standardized 
Table 2 Morphological and functional assessment of the cardiovascular system.

Reference

Electrocardiography

No of patients
(KS vS CTRL)

Findings

62 vs 62

132 vs 100
QTc-interval shorter in KS than in controls shortest in testosterone-treated KScomparable with controls in untreated KS

Pathologically short QTc times (<370 ms) were observed in $11 \mathrm{KS}$ patients but in none of the controls.

Effect was even more pronounced in those men with a paternal origin of the supernumerary $\mathrm{X}$ chromosome. Moreover, serum TS levels were not associated with QTc times

\section{Echocardiography}

(52) 22

(51) 22

(54) $\quad \mathrm{CR}$

(53) $\quad \mathrm{CR}$

(11) 69 vs 48

(14) 25 vs 25

Cardiopulmonary exercise test (11)

69 vs 48

(9)

Vascular assessment

(62)

(11)

$\mathrm{CR}$, case report; TS, testosterone
Increased prevalence of mitral valve prolapse (55\%)

No difference in LV architecture.Higher prevalence of mild diastolic dysfunction in KS compared with controls Subclinical alteration of the LV systolic function (reduction in LV strain and strain rate). High prevalence of $20 \%$ of diastolic dysfunction; in multiple regression analyses, E/A ratio (but not $E / E^{\prime}$ ratio) significantly correlated with truncal body fat

Marked reduction in $\mathrm{VO}_{2}$ peak and workload Increased prevalence of Chronotropic Incompetence: 25 out of $48(52 \%)$ vs no subjects in controls

Reduced VO2 uptake during exercise

No effect

No effect

No effect

Reduced diameters of brachial, common carotid, common femoral arteries and abdominal aorta arteries

No difference cIMT and FMD significant increase in carotid IMT
No effect

No effect

No effect
Effect of testosterone treatment (TST)
Mortality Ratio = 7.3). To the best of our knowledge, all cases of CCD in $\mathrm{KS}(68,70,71,72,73,74,75,76,77$, $78,79,80,81,82,83,84,85,86,87,88,89,90,91,92$, $93,94)$ are fully reported in the Supplemental Data 1 , see section on supplementary data given at the end of this article.

In summary, KS patients are characterized by subclinical abnormalities in LV subclinical systolic and diastolic function and endothelial function, which, together with chronotropic incompetence, may lead to impaired cardiopulmonary performance. Moreover, KS patients appear to be at a higher risk of CCD.

\section{Thrombosis and hemostasis in Klinefelter syndrome}

Data from large registry-based studies $(4,5,6,7)$ indicate that KS subjects are at increased risk of thromboembolic events. The hypothesis of an imbalance between thrombosis and hemostasis is suggested by the high prevalence $(7-13 \%)(95,96)$ of recurrent venous ulcers in KS (97), which in turn might be due to a previous post-thrombotic syndrome. Vein insufficiency is more prevalent in KS (about 20\%) than in the general population (98). The prevalence of mesenteric vein thrombosis and arterial ischemia/infarction (99) is moderately increased for $\operatorname{KS}(5,6,7,55,100)$. Moreover, a higher risk of both recurrent venous and artery thromboembolism has been shown in KS, with an HR of 2.15. Campbell et al. (95) found that the risk of deep venous thrombosis or pulmonary embolism was 5-20 times higher in KS than in normal males. Although excessive thromboembolic morbidity represents a significant burden in KS, no study has systematically explored the pathophysiological underpinnings of this phenomenon. However, despite scant available literature (most of data results from clinical 
cases or have a small sample size), some hypotheses maybe put forward: (i) vascular abnormalities and/or worse risk profile for venous thrombosis $(101,102,103,104)$; (ii) abnormalities in fibrinolysis with increased plasma activity of plasminogen activator inhibitor-1 (PAI-1) (105, $106,107,108,109,110)$; (iii) increased activity of factor VIII (111, 112); (iv) platelet hyperaggregability (113, 114). Recently, our group in an effort to evaluate platelet reactivity and the expression of platelet activation markers in KS has conducted a cross-sectional study. Twenty-three consecutive KS patients under testosterone replacement therapy have been included as a case group and 46 agematched healthy males recruited among hospital staff served as controls. We observed an increased platelet reactivity in KS (115); (v) deficit and inhibition of C and S proteins $(116,117,118,119,120,121,122,123)$; (vi) high levels of homocysteine associated with antithrombin III (AT-III) alterations (124) or other; (vii) factor V Leiden alterations $(125,126,127)$ (See Supplemental data 2 for details).

It is worth mentioning the role of testosterone replacement therapy in hemostasis. Although the direct and indirect physiological roles of testosterone and androgens on the coagulation system are well known $(128,129,130$, $131,132,133,134)$, there is currently no clear evidence about the impact of hormone replacement therapy on the risk of venous thromboembolism in patients with KS.
Some case reports showed an improvement of leg ulcers and laboratory parameters with replacement therapy (110, $111,122,123,135)$ (see Supplemental data 2). On the other hand, some authors suggested a detrimental role of testosterone therapy on the hemostatic balance (136). In the study by Di Minno et al. (115), no correlation between increased platelet reactivity and testosterone and estradiol levels in KS subjects studied under testosterone replacement therapy (115) was found. However, only patients receiving hormonal replacement therapy were evaluated, thus limiting the study's conclusions.

Consequently, the role of testosterone replacement therapy in thromboembolic risk in KS patients is still unclear. Controlled studies are needed for attempting to find a definitive pathophysiological explanation for the thrombophilic alterations characterizing KS. It is important to emphasize that KS should be considered in the differential diagnosis of a male patient with nonhealing ulcers of the lower extremities.

In summary, KS patients are characterized by an increased risk of thromboembolic events with high prevalence of recurrent venous ulcers, vein insufficiency, both recurrent venous and artery thromboembolism with higher risk of deep venous thrombosis or pulmonary embolism than general population. To date, there is no clear evidence of the impact of hormone replacement therapy on the risk of venous thromboembolism in patients with KS.

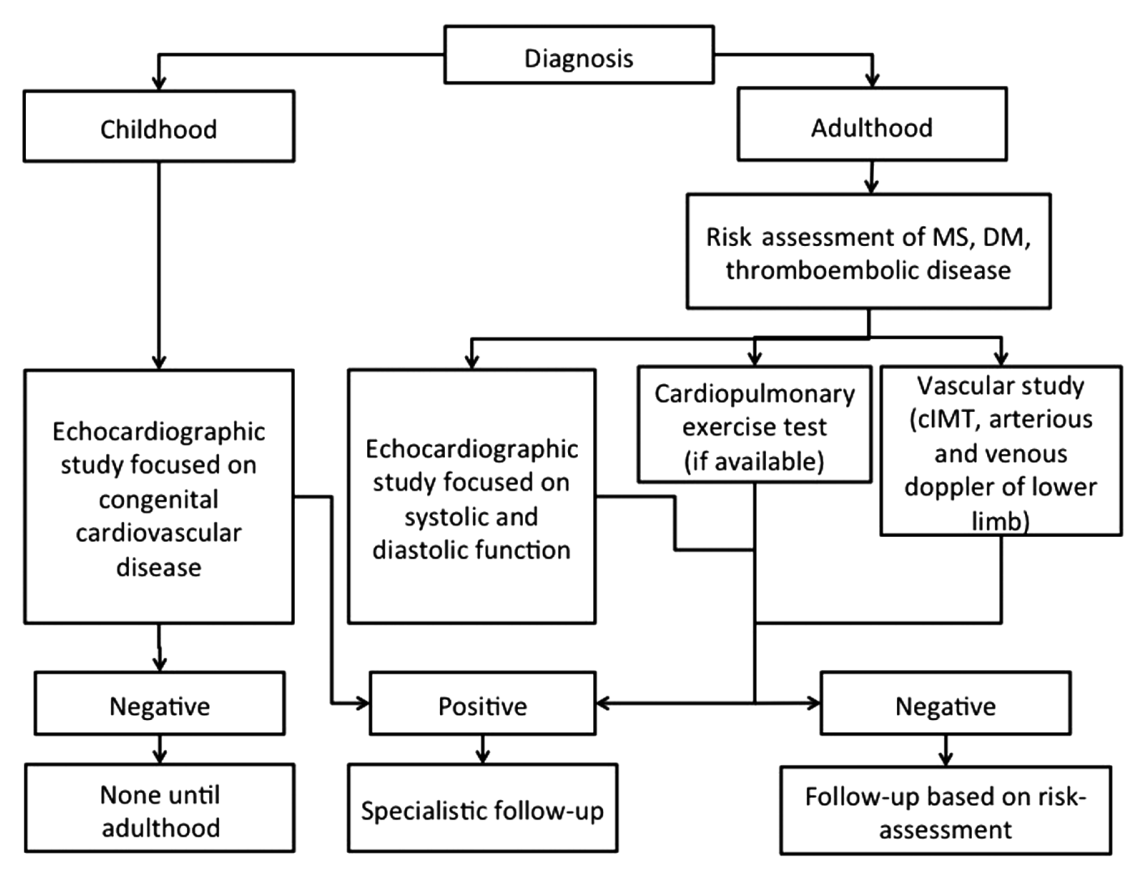

Figure 1

Suggested flow-chart for cardiovascular and metabolic assessment and follow-up in Klinefelter syndrome. 


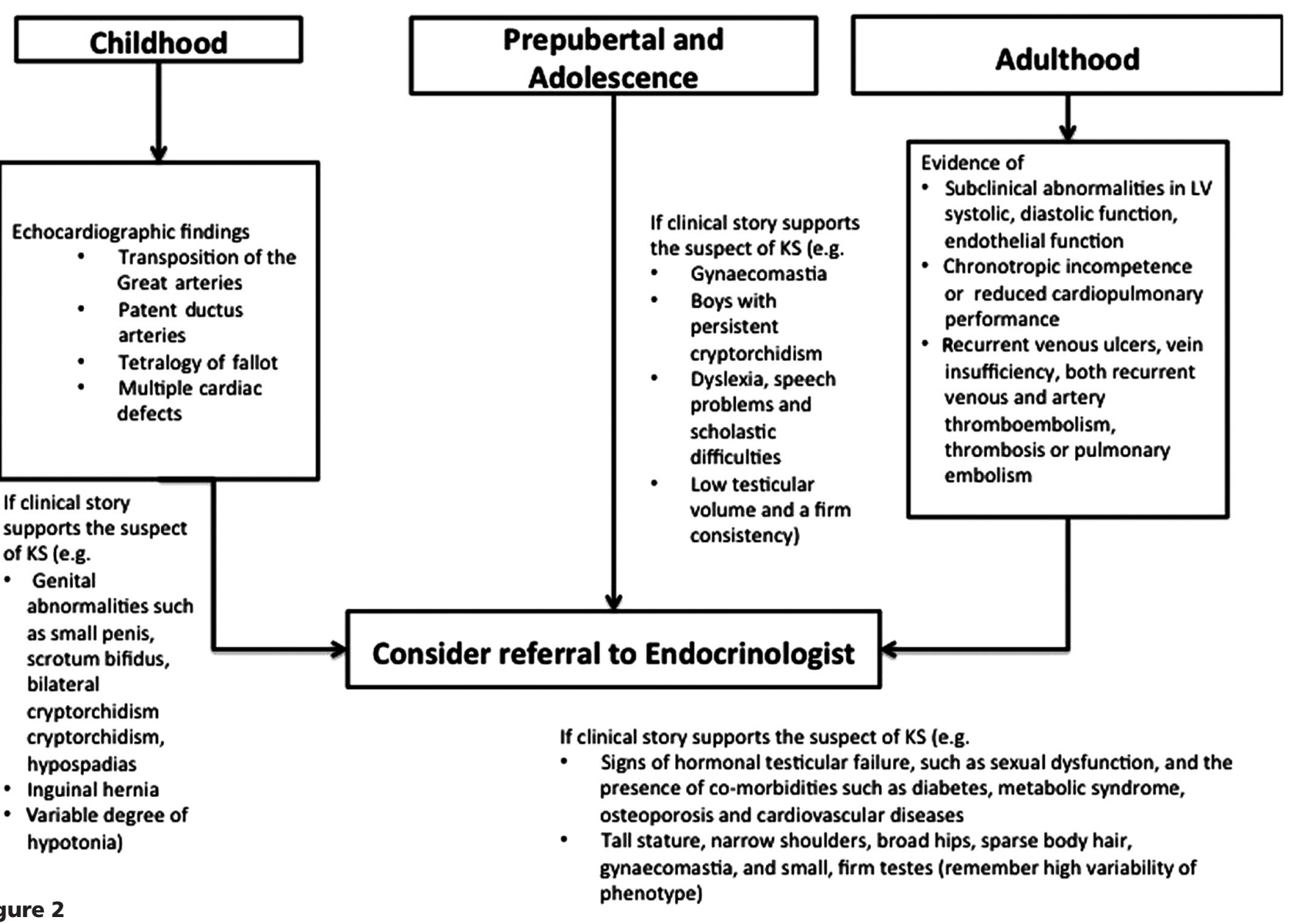

Figure 2

Suggested flow-chart for endocrinology referral by cardiologists diagnosing cardiovascular abnormalities potentially associated to KS.

\section{Are the cardiovascular abnormalities in Klinefelter syndrome due to hypogonadism or to the syndrome itself?}

To date, two main hypotheses might be put forward to explain the cardiovascular involvement in KS subjects: is the hypogonadism the main player responsible for cardiovascular involvement in KS or is the KS per se the culprit? In the following section, both hypotheses were briefly discussed.

Hypogonadism may play a pivotal role in determining some conditions including MS and dyslipidemia that, in turn, may impact on exercise capacity and overall cardiovacular status. However, the lack of evidence that testosterone replacement therapy might improve exercise capacity, skeletal muscle performance, insulin resistance in KS (11) at variance with data reported in the general population (137) does not support a prominent pathophysiological role of hypogonadism. In this complex scenario, it is worth pointing out that the clinical response to testosterone therapy is influenced by the polymorphism of the gene encoding for the X-linked androgen receptor gene, which is characterized by a certain number of CAG repeats (CAGn) (the length of the CAGn is inversely associated with androgen sensitivity) $(18,138)$. A high number of CAGn is a common finding in KS genotype, and it may significately modulate the clinical response to testosterone therapy (18). Bojesen and coworkers demonstrated an impact of the CAGn polymorphism on the phenotype of KS. In this study, involving $70 \mathrm{KS}$ patients and 70 agematched control subjects, they showed that although the number of CAG repeats was not different from controls, it did affect height, arm span, total cholesterol, hemoglobin, and hematocrit within the KS cohort, but did not impact the effect of testosterone treatment in KS (139).

Pasquali et al. (11) recently proposed that the chromosomal abnormality plays a major role in inducing cardiovascular phenotype of KS patients. In this study, the authors specifically studied a group of normal karyotype hypogonadal patients under adequate testosterone replacement therapy, who displayed a normalization of the cardiovascular abnormalities that did not occur in matched KS patients under similar replacement regimens. 
Despite these studies not being specifically designed to provide mechanistic insights into the pathophysiology of the abnormalities found in KS, these observations suggest a complex interaction between chromosomal and hormonal factors (chromosomal abnormality is associated with clinical response to hormones), being the testosterone action on target tissues as the actual deficient process.

KS might represent a natural human model of androgen deprivation. Given the known properties of testosterone on the cardiovascular system $(140,141,142,143$, $144)$, it may be relevant to study these young subjects with regard to the cardiovascular function and determine the effects of a long-term testosterone deficiency/insensitivity.

In conclusion, it could be argued that cardiovascular involvement in KS is mainly due to chromosomal abnormalities rather than to low serum testosterone levels. However, the chromosomopathy maybe strictly related to the magnitude of the testosterone activity on the tissues. In addition, an alteration of androgen pulses or release from the testis has been recently hypothesized (65). An alteration of the release from the testes due to an impaired testicular vascular bed could be responsible either for lower circulating levels or impaired secretory rhythm.

\section{Clinical implications}

Patients affected by KS display an impaired metabolic risk profile characterized by an increased prevalence of MS and DM. This may lead to subclinical systolic and diastolic dysfunction and vascular abnormalities, which in turn might sustain the impaired cardiopulmonary performance. In most studies, the subtle cardiovascular abnormalities were not reverted by testosterone replacement. It seems reasonable to consider, in the medical management of KS $(13,30,145,146,147,148,149)$, a complete cardiovascular work-up in KS patients, in order to diagnose and correct preclinical and clinical abnormalities, with the aim of an overall reduction of the cardiovascular risk.

Specifically, if KS diagnosis is made during childhood, all patients should undergo a complete echocardiographic study to look for possible cardiac abnormalities. If the diagnosis of KS is made during adulthood, echocardiographic study should be focused on preclinical systolic and diastolic dysfunction. If no alterations are found, patients need follow-up based on available risk-assessment (150, 151) (Fig. 1).

Considering the risk of overlooking the underlying diagnosis of KS, we suggest a flowchart to guide the cardi- ologists to select the right patient to consider for endocrinologic consultation (Fig. 2).

Considering the unequivocal finding of an increased mortality of KS patients mostly related to cardiovascular disease, more research is needed to characterize these alterations and explain the underlying pathophysiological background.

\section{Supplementary data}

This is linked to the online version of the paper at http://dx.doi.org/10.1530/ EJE-15-1025

Declaration of interest

The authors declare that there is no conflict of interest that could be perceived as prejudicing the impartiality of the research reported.

\section{Funding}

This research did not receive any specific grant from any funding agency in the public, commercial, or not-for-profit sector.

\section{Acknowledgments}

The authors thank Mara Valentin Garcia, M.S. (Pediatric Cardiac Sonographer) for her assistance in reviewing this manuscript.

\section{References}

1 Bojesen A, Juul S \& Gravholt CH. Prenatal and postnatal prevalence of Klinefelter syndrome: a national registry study. Journal of Clinical Endocrinology \& Metabolism 200388 622-626.

2 Morris JK, Alberman E, Scott C \& Jacobs P. Is the prevalence of Klinefelter syndrome increasing? European Journal of Human Genetics 200816 163-170. (doi:10.1038/sj.ejhg.5201956)

3 Klinefelter HF Jr, Reifenstein EC, Albright F. Syndrome characterized by gynaecomastia, aspermatogenesis without a-Leydigism, and increased excretion of follicle stimulating hormone. Journal of Clinical Endocrinology \& Metabolism 19422 615-627.

4 Bojesen A \& Gravholt CH. Morbidity and mortality in Klinefelter syndrome (47,XXY). Acta Paediatrica 2011100 807-813. (doi:10.1186/s13567-016-0320-6)

5 Bojesen A, Juul S, Birkebaek N \& Gravholt CH. Increased mortality in Klinefelter syndrome. Journal of Clinical Endocrinology \& Metabolism 200489 3830-3834. (doi:10.1210/jc.2004-0777)

6 Bojesen A, Juul S, Birkebaek NH \& Gravholt CH. Morbidity in Klinefelter syndrome: a Danish register study based on hospital discharge diagnoses. Journal of Clinical Endocrinology \& Metabolism 200691 1254-1260. (doi:10.1210/jc.2005-0697)

7 Swerdlow AJ, Higgins CD, Schoemaker MJ, Wright AF \& Jacobs PA. Mortality in patients with Klinefelter syndrome in Britain: a cohort study. Journal of Clinical Endocrinology \& Metabolism 200590 6516-6522. (doi:10.1210/jc.2008-1049)

8 Price WH, Clayton JF, Collyer S \& de Mey R. Mortality ratios and life expectancy in X chromatin positive males. Journal of Epidemiology and Community Health 198539 33-38. (doi:10.1136/jech.41.1.1)

9 Bojesen A, Kristensen K, Birkebaek NH, Fedder J, Mosekilde L, Bennett P, Laurberg P, Frystyk J, Flyvbjerg A, Christiansen JS et al. The metabolic syndrome is frequent in Klinefelter's syndrome and is 
associated with abdominal obesity and hypogonadism. Diabetes Care 200629 1591-1598.

10 Ishikawa T, Yamaguchi K, Kondo Y, Takenaka A \& Fujisawa M. Metabolic syndrome in men with Klinefelter's syndrome. Urology 200871 1109-1113. (doi:10.1016/j.urology.2008.01.051)

11 Pasquali D, Arcopinto M, Renzullo A, Rotondi M, Accardo G, Salzano A, Esposito D, Saldamarco L, Isidori AM, Marra AM et al. Cardiovascular abnormalities in Klinefelter syndrome. International Journal of Cardiology 2013168 754-759. (doi:10.1016/j. ijcard.2012.09.215)

12 Bardsley MZ, Falkner B, Kowal K \& Ross JL. Insulin resistance and metabolic syndrome in prepubertal boys with Klinefelter syndrome. Acta Paediatrica 2011100 866-870. (doi:10.1111/apa.2011.100.issue-6)

13 Aksglaede L, Link K, Giwercman A, Jorgensen N, Skakkebaek NE \& Juul A. 47,XXY Klinefelter syndrome: clinical characteristics and age-specific recommendations for medical management. American Journal of Medical Genetics Part C: Seminars in Medical Genetics 2013 163C 55-63.

14 Andersen NH, Bojesen A, Kristensen K, Birkebaek NH, Fedder J, Bennett P, Christiansen JS \& Gravholt CH. Left ventricular dysfunction in Klinefelter syndrome is associated to insulin resistance, abdominal adiposity and hypogonadism. Clinical Endocrinology 200869 785-791. (doi:10.1111/cen.2008.69.issue-5)

15 Rotondi M, Coperchini F, Renzullo A, Accardo G, Esposito D, Groppelli G, Magri F, Cittadini A, Isidori AM, Chiovato L et al. High circulating levels of CCL2 in patients with Klinefelter's syndrome. Clinical Endocrinology 201480 465-467. (doi:10.1111/cen.12245)

16 Ferlin A, Schipilliti M, Vinanzi C, Garolla A, Di Mambro A, Selice R, Lenzi A \& Foresta C. Bone mass in subjects with Klinefelter syndrome: role of testosterone levels and androgen receptor gene CAG polymorphism. Journal of Clinical Endocrinology \& Metabolism 201196 E739-E745. (doi:10.1210/jc.2010-1878)

17 Meurer M, Kuhnle U, Lindl U \& Keller U. Androgen receptors in Klinefelter's syndrome. Lancet 1993341 1351. (doi:10.1016/09600760(94)90081-7)

18 Zitzmann M, Depenbusch M, Gromoll J \& Nieschlag E. $\mathrm{X}$-chromosome inactivation patterns and androgen receptor functionality influence phenotype and social characteristics as well as pharmacogenetics of testosterone therapy in Klinefelter patients. Journal of Clinical Endocrinology \& Metabolism 200489 6208-6217. (doi:10.1210/jc.2004-1424)

19 Mirouze J, Jaffiol C, Bernard C \& Cartry E. The prediabetes of Klinefelter's syndrome. Diabete 196614 57-59.

20 Nielsen J, Johansen K \& Yde H. Frequency of diabetes mellitus in patients with Klinefelter's syndrome of different chromosome constitutions and the XYY syndrome. Plasma insulin and growth hormone level after a glucose load. Journal of Clinical Endocrinology \& Metabolism 196929 1062-1073.

21 Jackson IM, Buchanan KD, McKiddie MT \& Prentice CR Carbohydrate metabolism in Klinefelter's syndrome. Journal of Endocrinology 196635 169-172. (doi:10.1016/S0140-6736(71)92625-0)

22 Becker KL, Hoffman DL, Underdahl LO \& Mason HL. Klinefelter's syndrome. Clinical and laboratory findings in 50 patients. Archives of Internal Medicine 1966118 314-321. (doi:10.1001/archi nte.1966.00290160014004)

23 Takeuchi Y, Murata Y, Sintani J, Masukawa H, Nakamura R, Oi K, Kato Y \& Niinomi M. Klinefelter's syndrome accompanied by mixed connective tissue disease and diabetes mellitus. Internal Medicine 199938 875-881. (doi:10.2169/internalmedicine.38.875)

24 Ota K, Suehiro T, Ikeda Y, Arii K, Kumon Y \& Hashimoto K. Diabetes mellitus associated with Klinefelter's syndrome: a case report and review in Japan. Internal Medicine 200241 842-847. (doi:10.1016/j. atherosclerosis.2008.05.013)

25 Milcou SM, Ionesco B \& Bucur A. Glucide metabolism in Klinefelter's disease. La Revue française d'endocrinologie clinique 197112 305-314.
26 Esmann V, Nielsen J \& Petersen GB. A case of Klinefelter's syndrome with 48,XXXY and diabetes mellitus. Acta Medica Scandinavica 1969 186 27-33.

27 Corona G, Maseroli E, Rastrelli G, Isidori AM, Sforza A, Mannucci E \& Maggi M. Cardiovascular risk associated with testosterone-boosting medications: a systematic review and meta-analysis. Expert Opinion on Drug Safety 201413 1327-1351. (doi:10.1517/14740338.2014.950653)

28 Fernandez-Balsells MM, Murad MH, Lane M, Lampropulos JF, Albuquerque F, Mullan RJ, Agrwal N, Elamin MB, Gallegos-Orozco JF, Wang AT et al. Clinical review 1: adverse effects of testosterone therapy in adult men: a systematic review and meta-analysis. Journal of Clinical Endocrinology \& Metabolism 201095 2560-2575.

29 Isidori AM, Balercia G, Calogero AE, Corona G, Ferlin A, Francavilla S, Santi D \& Maggi M. Outcomes of androgen replacement therapy in adult male hypogonadism: recommendations from the Italian society of endocrinology. Journal of Endocrinological Investigation 201538 103-112. (doi:10.1007/ s40618-014-0155-9)

30 Lanfranco F, Kamischke A, Zitzmann M \& Nieschlag E. Klinefelter's syndrome. The Lancet 2004364 273-283. (doi:10.1016/S01406736(04)16678-6)

31 Koenig W, Sund M, Frohlich M, Fischer HG, Lowel H, Doring A, Hutchinson WL \& Pepys MB. C-reactive protein, a sensitive marker of inflammation, predicts future risk of coronary heart disease in initially healthy middle-aged men: results from the MONICA (Monitoring Trends and Determinants in Cardiovascular Disease) Augsburg cohort study, 1984 to 1992. Circulation 199999 237-242.

32 Host C, Bojesen A, Frystyk J, Flyvbjerg A, Christiansen JS \& Gravholt $\mathrm{CH}$. Effect of sex hormone treatment on circulating adiponectin and subforms in Turner and Klinefelter syndrome. European Journal of Clinical Investigation 201040 211-219. (doi:10.1111/eci.2010.40.issue-3)

33 Schmidt-Lucke C, Rossig L, Fichtlscherer S, Vasa M, Britten M, Kamper U, Dimmeler S \& Zeiher AM. Reduced number of circulating endothelial progenitor cells predicts future cardiovascular events: proof of concept for the clinical importance of endogenous vascular repair. Circulation 2005111 2981-2987. (doi:10.1161/ CIRCULATIONAHA.104.504340)

34 Vasa M, Fichtlscherer S, Aicher A, Adler K, Urbich C, Martin H, Zeiher AM \& Dimmeler S. Number and migratory activity of circulating endothelial progenitor cells inversely correlate with risk factors for coronary artery disease. Circulation Research 200189 E1-E7. (doi:10.1161/hh1301.093953)

35 Vasa M, Fichtlscherer S, Adler K, Aicher A, Martin H, Zeiher AM \& Dimmeler S. Increase in circulating endothelial progenitor cells by statin therapy in patients with stable coronary artery disease. Circulation 2001103 2885-2890. (doi:10.1172/JCI200113152)

36 Di Mambro, Ferlin A, De Toni L, Selice R, Caretta N \& Foresta C. Endothelial progenitor cells as a new cardiovascular risk factor in Klinefelter's syndrome. Molecular Human Reproduction 201016 411-417. (doi:10.1093/molehr/gaq015)

37 Foresta C, Caretta N, Lana A, De Toni L, Biagioli A, Ferlin A \& Garolla A. Reduced number of circulating endothelial progenitor cells in hypogonadal men. Journal of Clinical Endocrinology \& Metabolism 200691 4599-4602. (doi:10.1016/j.eururo.2006.08.052)

38 Foresta C, Ferlin A, De Toni L, Lana A, Vinanzi C, Galan A \& Caretta N. Circulating endothelial progenitor cells and endothelial function after chronic Tadalafil treatment in subjects with erectile dysfunction. International Journal of Impotence Research $2006 \mathbf{1 8}$ 484-488. (doi:10.1038/sj.ijir.3901465)

$39 \mathrm{Ru}$ BZ, Gao XC, Yue WW \& Hu P. Testosterone level not significantly correlates to endothelial progenitor cells in Klinefelter's syndrome patients. Zhonghua Nan Ke Xue 201218 67-69.

40 Sanchez-Hernandez Y, Laforenza U, Bonetti E, Fontana J, Dragoni S, Russo M, Avelino-Cruz JE, Schinelli S, Testa D, Guerra G et al. Store- 
operated $\mathrm{Ca}(2+)$ entry is expressed in human endothelial progenitor cells. Stem Cells and Development 201019 1967-1981.

41 Moccia F, Dragoni S, Lodola F, Bonetti E, Bottino C, Guerra G, Laforenza U, Rosti V \& Tanzi F. Store-dependent $\mathrm{Ca}(2+)$ entry in endothelial progenitor cells as a perspective tool to enhance cell-based therapy and adverse tumour vascularization. Current Medicinal Chemistry 201219 5802-5818.

42 Moccia F, Lodola F, Dragoni S, Bonetti E, Bottino C, Guerra G, Laforenza U, Rosti V \& Tanzi F. Ca2+ signalling in endothelial progenitor cells: a novel means to improve cell-based therapy and impair tumour vascularisation. Current Vascular Pharmacology 2014 12 87-105.

43 Dragoni S, Laforenza U, Bonetti E, Reforgiato M, Poletto V, Lodola F, Bottino C, Guido D, Rappa A, Pareek S et al. Enhanced expression of Stim, Orai, and TRPC transcripts and proteins in endothelial progenitor cells isolated from patients with primary myelofibrosis. PLoS One 20149 e91099.

44 Lodola F, Laforenza U, Bonetti E, Lim D, Dragoni S, Bottino C, Ong HL, Guerra G, Ganini C, Massa M et al. Store-operated Ca2+ entry is remodelled and controls in vitro angiogenesis in endothelial progenitor cells isolated from tumoral patients. PLoS One 20127 e42541.

45 Friedman JM. Leptin, leptin receptors, and the control of body weight. Nutrition Reviews 199856 s38-s46; discussion s54-s75.

46 Adamczak M, Wiecek A, Funahashi T, Chudek J, Kokot F \& Matsuzawa Y. Decreased plasma adiponectin concentration in patients with essential hypertension. American Journal of Hypertension 200316 72-75. (doi:10.1159/000085707)

47 Kumada M, Kihara S, Sumitsuji S, Kawamoto T, Matsumoto S, Ouchi N, Arita Y, Okamoto Y, Shimomura I, Hiraoka H et al. Association of hypoadiponectinemia with coronary artery disease in men. Arteriosclerosis, Thrombosis, and Vascular Biology 200323 85-89. (doi:10.1161/01.ATV.0000048856.22331.50)

48 Saely CH, Risch L, Hoefle G, Rein P, Muendlein A, Marte T, Aczel S, Langer $\mathrm{P} \&$ Drexel $\mathrm{H}$. Low serum adiponectin is independently associated with both the metabolic syndrome and angiographically determined coronary atherosclerosis. Clinica Chimica Acta 2007383 97-102.

49 Jorgensen IN, Skakkebaek A, Andersen NH, Pedersen LN, Hougaard DM, Bojesen A, Trolle C \& Gravholt CH. Short QTc interval in males with klinefelter syndrome-influence of CAG repeat length, body composition, and testosterone replacement therapy. Pacing and Clinical Electrophysiology 201538 472-482. (doi:10.1111/ pace.12580)

50 Zitzmann M, Bongers R, Werler S, Bogdanova N, Wistuba J, Kliesch S, Gromoll J \& Tuttelmann F. Gene expression patterns in relation to the clinical phenotype in Klinefelter syndrome. Journal of Clinical Endocrinology \& Metabolism 2015100 E518-E523. (doi:10.1210/jc.2014-2780)

51 Karagoz A, Dikbas O, Teker E, Vural A, Gunaydin ZY \& Bektas O. Sinus node dysfunction requiring permanent pacemaker implantation in a young adult with Klinefelter syndrome. American Journal of Case Reports 201516 136-139. (doi:10.12659/ AJCR.893065)

52 Fricke GR, Mattern HJ, Schweikert HU \& Schwanitz G. Klinefelter's syndrome and mitral valve prolapse. an echocardiographic study in twenty-two patients. Biomedicine \& Pharmacotherapy 198438 88-97.

53 Fricke GR, Mattern HJ \& Schweikert HU. Mitral valve prolapse in Klinefelter syndrome. Lancet 198121414.

54 Ueki Y, Izawa A, Ebisawa S, Motoki H, Miyashita Y, Tomita T, Koyama J, Takano T, Amano J \& Ikeda U. Infective endocarditis associated with mitral valve prolapse in a patient with Klinefelter syndrome. Internal Medicine 201453 969-972.

55 Murray FE. Mesenteric vein thrombosis associated with Klinefelters syndrome - a case report. Angiology 198839 45-48. (doi:10.1177/00 0331978803900107)
56 Fang ZY, Leano R \& Marwick TH. Relationship between longitudinal and radial contractility in subclinical diabetic heart disease. Clinical Science (London) 2004106 53-60. (doi:10.1136/ heartjnl-2014-307391)

57 Di Bello V, Santini F, Di Cori A, Pucci A, Palagi C, Delle Donne MG, Giannetti M, Talini E, Nardi C, Pedrizzetti G et al. Relationship between preclinical abnormalities of global and regional left ventricular function and insulin resistance in severe obesity: a Color Doppler imaging study. International Journal of Obesity (London) 2006 30 948-956.

58 Cittadini A, Marra AM, Arcopinto M, Bobbio E, Salzano A, Sirico D, Napoli R, Colao A, Longobardi S, Baliga RR et al. Growth hormone replacement delays the progression of chronic heart failure combined with growth hormone deficiency: an extension of a randomized controlled single-blind study. JACC: Heart Failure $20131325-330$. (doi:10.1016/j.jchf.2013.04.003)

59 Brubaker PH \& Kitzman DW. Chronotropic incompetence: causes, consequences, and management. Circulation 2011123 1010-1020. (doi:10.1097/HCR.0000000000000175)

60 Lauer MS, Francis GS, Okin PM, Pashkow FJ, Snader CE \& Marwick TH. Impaired chronotropic response to exercise stress testing as a predictor of mortality. Journal of the American Medical Association 1999281 524-529. (doi:10.1001/jama.281.6.524)

61 Chambless LE, Heiss G, Folsom AR, Rosamond W, Szklo M, Sharrett AR \& Clegg LX. Association of coronary heart disease incidence with carotid arterial wall thickness and major risk factors: the Atherosclerosis Risk in Communities (ARIC) study, 1987-1993. American Journal of Epidemiology 1997146 483-494. (doi:10.1093/ oxfordjournals.aje.a009302)

62 Lorenz MW, Markus HS, Bots ML, Rosvall M \& Sitzer M. Prediction of clinical cardiovascular events with carotid intima-media thickness: a systematic review and meta-analysis. Circulation 2007 115 459-467. (doi:10.1161/CIRCULATIONAHA.106.628875)

63 Foresta C, Caretta N, Palego P, Ferlin A, Zuccarello D, Lenzi A $\&$ Selice R. Reduced artery diameters in Klinefelter syndrome. International Journal of Andrology 201235 720-725. (doi:10.1111/ ija.2012.35.issue-5)

64 Stein JH, Korcarz CE, Hurst RT, Lonn E, Kendall CB, Mohler ER, Najjar SS, Rembold CM, Post WS \& American Society of Echocardiography carotid intima-media thickness task force. Use of carotid ultrasound to identify subclinical vascular disease and evaluate cardiovascular disease risk: a consensus statement from the American Society of Echocardiography Carotid Intima-Media Thickness Task Force. Endorsed by the Society for Vascular Medicine. Journal of the American Society of Echocardiography 20082193 111; quiz 189190.

65 Tuttelmann F, Damm OS, Luetjens CM, Baldi M, Zitzmann M, Kliesch S, Nieschlag E, Gromoll J, Wistuba J \& Simoni M. Intratesticular testosterone is increased in men with Klinefelter syndrome and may not be released into the bloodstream owing to altered testicular vascularization - a preliminary report. Andrology $20142275-281$.

66 Radicioni AF, De Marco E, Gianfrilli D, Granato S, Gandini L, Isidori AM \& Lenzi A. Strategies and advantages of early diagnosis in Klinefelter's syndrome. Molecular Human Reproduction 201016 434-440. (doi:10.1093/molehr/gaq027)

67 Panimolle F, Tiberti C, Granato S, Semeraro A, Gianfrilli D, Anzuini A, Lenzi A \& Radicioni A. Screening of endocrine organ-specific humoral autoimmunity in 47,XXY Klinefelter's syndrome reveals a significant increase in diabetes-specific immunoreactivity in comparison with healthy control men. Endocrine 201549 606-610. (doi:10.1007/s12020-015-0613-y)

68 Emerit I, de Grouchy J, Vernant P \& Corone P. Chromosomal abnormalities and congenital heart disease. Circulation 196736 886-905. 
69 Blue GM, Kirk EP, Sholler GF, Harvey RP \& Winlaw DS. Congenita heart disease: current knowledge about causes and inheritance. Medical Journal of Australia 2012197 155-159. (doi:10.1016/j. jacc.2014.09.048)

70 Yin M, Dong L, Zheng J, Zhang H, Liu J \& Xu Z. Meta analysis of the association between MTHFR C677T polymorphism and the risk of congenital heart defects. Annals of Human Genetics 201276 9-16. (doi:10.1111/ahg.2012.76.issue-1)

71 Adatia I, Coe JY \& Harder J. Transposition of the great arteries in a neonate with Klinefelter's syndrome. Pediatric Cardiology 19878 285-286. (doi:10.1371/journal.pone.0143146)

72 Liu J, Moulick A, Mesia CI, Ge S, Obiri N \& Anderson CE Transposition of the great arteries in a neonate with Klinefelter syndrome-an incidental finding or a true association. American Journal of Medical Genetics Part A 2015 167A 268-270. (doi:10.1002/ ajmg.a.36814)

73 Rohde RA. The chromosomes in heart disease. Clinical and cytogenetic studies of sixty-eight cases. Circulation 196634 484-502. (doi:10.1161/01.CIR.34.3.484)

74 Zhang Y. Congenital defect of the partial atrioventricular canal with Klinefelter syndrome. BMJ Case Reports 2009 bcr10.2008.1121. (doi:10.1136/bcr.10.2008.1121)

75 Gautier M \& Nouaille J. Systematic study of the Barr body in 500 infants with severe congenital heart diseases. Archives Françaises de Pédiatrie 196724109.

76 Velagaleti GV, Kumar A, Lockhart LH \& Matalon R. Patent ductus arteriosus and microdeletion 22q11 in a patient with Klinefelter syndrome. Annales de Génétique 200043 105-107. (doi:10.1016/ S0003-3995(00)01013-3)

77 Yoshida K, Ryu T, Ogata T, Tsuji S, Tokushima T, Utsunomiya T \& Matsuo S. An elderly man with Klinefelter syndrome associated with hypertrophic cardiomyopathy, sick sinus syndrome, and coronary arteriovenous fistula. Japanese Circulation Journal 199862 222-224 (doi:10.1536/jhj.41.723)

78 Rosenthal A. Cardiovascular malformations in Klinefelter's syndrome: report of three cases. Journal of Pediatrics $1972 \mathbf{8 0}$ 471-473. (doi:10.1016/S0022-3476(72)80509-2)

79 Peet J, Weaver DD \& Vance GH. 49,XXXXY: a distinct phenotype. Three new cases and review. Journal of Medical Genetics 199835 420-424. (doi:10.1136/jmg.35.5.420)

80 Agarwal S \& Dekam MJ. Multiple cardiac anomalies in an elderly man with Klinefelter's syndrome. Singapore Medical Journal 201152 e15-e17.

81 Shen Z, Zou CC, Shang SQ, \& Jiang KW. Down-Klinefelter syndrome $(48, \mathrm{XXY},+21)$ in a child with congenital heart disease: case report and literature review. Internal Medicine 201251 1371-1374. (doi:10.2169/internalmedicine.51.7097)

82 Hustinx TW, Eberle P, Geerts SJ, ten B \& Woltring LM. Mongoloid twins with 48 chromosomes (AA plus A21XXY). Annals of Human Genetics 196125 111-115. (doi:10.1111/ahg.1961.25.issue-2)

83 Serra W, De Iaco G, Reverberi C \& Gherli T. Pulmonary embolism and patent foramen ovale thrombosis: the key role of TEE. Cardiovascular Ultrasound 20075 26. (doi:10.1186/1476-7120-5-26)

84 De Grouchy J, Emerit I, De Gennes JL \& Vernant P. [Klinefelter's syndrome in a 6-year-old trisomy-21 boy. La Presse Médicale 196573 1209-1212.

85 Hecht F, Nievaard JE, Duncanson N, Miller JR, Higgins JV, Kimberling WJ, Walker FA, Smith GS, Thuline HC \& Tischler B. Double aneuploidy: the frequency of XXY in males with Down's syndrome. The American Journal of Human Genetics 196921 352-359.

86 Erdtmann B, de Freitas AA, de Souza RP \& Salzano FM. Klinefelter's syndrome and G trisomy. Journal of Medical Genetics 1971 8 364-368. (doi:10.1136/jmg.8.3.364)

87 Efinski D, Duma H, Apostolovski B, Sofijanov N, Ristevski B \& Darkovski S. Klinefelter's and Down's syndrome in an adolescent with abnormal EEG. Clinical Genetics 19745 81-85.
88 Akbas E, Soylemez F, Savasoglu K, Halliogluand O \& Balci S. A male case with double aneuploidy $(48, \mathrm{XXY},+21)$. Genetic Counseling 2008 19 59-63.

89 Gerretsen MF, Peelen W, Rammeloo LA, Koolbergen DR \& Hruda J. Double aortic arch with double aneuploidy - rare anomaly in combined Down and Klinefelter syndrome. European Journal of Pediatrics 2009168 1479-1481. (doi:10.1007/s00431-009-0958-4)

90 Jeanty C \& Turner C. Prenatal diagnosis of double aneuploidy, $48, \mathrm{XXY},+21$, and review of the literature. Journal of Ultrasound in Medicine 200928 673-681. (doi:10.1016/j.jpedsurg.2014.08.019)

91 Said SA, Bucx JJ \& van de Weel FA. Coronary-cameral fistula in association with Klinefelter syndrome: exercise-induced ventricular tachycardia late after surgical ligation. International Journal of Cardiology 199236 111-114. (doi:10.1093/eurheartj/14.7.999)

92 Hou JW. 49, XXXXY syndrome. Chang Gung Medical Journal 200427 551-554.

93 Ford CE, Jones KW, Miller OJ, Mittwoch U, Penrose LS, Ridler M \& Shapiro A. The chromosomes in a patient showing both mongolism and the Klinefelter syndrome. The Lancet 19591 709-710.

94 Harnden DG, Miller OJ \& Penrose LS. The Klinefeltermongolism type of double aneuploidy. Annals of Human Genetics 196024 165-169. (doi:10.1111/ahg.1959.24.issue-2)

95 Campbell WA \& Price WH. Venous thromboembolic disease in Klinefelter's syndrome. Clinical Genetics 198119 275-280. (doi:10.1021/acs.biochem.5b00900)

96 Campbell WA, Newton MS \& Price WH. Hypostatic leg ulceration and Klinefelter's syndrome. Journal of Mental Deficiency Research 1980 24 115-117.

97 Yabuno Y, Tosa M, Iwakiri I, Nomoto S, Kaneko M, Kuwahara K, Hyakusoku H \& Murakami M. Refractory leg ulcers associated with klinefelter syndrome. Journal of Nippon Medical School 201582 64-67. (doi:10.1272/jnms.82.64)

98 Becker KL. Clinical and therapeutic experiences with Klinefelter's syndrome. Fertility and Sterility 197223 568-578.

99 Rouffy J, Pestel M, Cortot A, Sikorav H, Michaux A \& Julien R. Klinefelter's syndrome, endogenous hypertriglyceridemia, and arteriopathy of the lower limbs. Apropos of a case. Annales de Médecine Interne (Paris) 1973124 201-206.

100 Okayama S, Uemura S \& Saito Y. Hypertrophic cardiomyopathy and mesenteric venous thrombosis in a patient with Klinefelter syndrome. International Journal of Cardiology 2013166 e50-e52. (doi:10.1253/circj.CJ-15-0425)

101 Verp MS, Simpson JL \& Martin AO. Hypostatic ulcers in 47,XXY Klinefelter's syndrome. Journal of Medical Genetics 198320 100-101.

102 Howell R. Hypostatic ulceration and Klinefelter's syndrome. British Medical Journal 19782 95-96. (doi:10.1136/bmj.2.6130.95-a)

103 Angel JR, Parker S, Sells RE \& Atallah E. Recurrent deep vein thrombosis and pulmonary embolism in a young man with Klinefelter's syndrome and heterozygous mutation of MTHFR677C >T and 1298A>C. Blood Coagulation \& Fibrinolysis 201021 372-375. (doi:10.1097/MBC.0b013e32833894eb)

104 Wierda E, Reesink HJ, Bruining H, van Delden OM, Kloek JJ \& Bresser P. Successful pulmonary endarterectomy in a patient with klinefelter syndrome. Case Reports in Pulmonology 20122012 104195.

105 Iwaki T, Urano T \& Umemura K. PAI-1, progress in understanding the clinical problem and its aetiology. British Journal of Haematology 2012157 291-298. (doi:10.5414/CP202001)

106 Zollner TM, Veraart JC, Wolter M, Hesse S, Villemur B, Wenke A, Werner RJ, Boehncke WH, Jost SS, Scharrer I et al. Leg ulcers in Klinefelter's syndrome - further evidence for an involvement of plasminogen activator inhibitor-1. British Journal of Dermatology 1997136 341-344.

107 Veraart JC, Hamulyak K, Neumann HA \& Engelen J. Increased plasma activity of plasminogen activator inhibitor 1 (PAI-1) in two patients with Klinefelter's syndrome complicated by leg ulcers. 
British Journal of Dermatology 1994130 641-644. (doi:10.1111/ j.1365-2133.1994.tb13112.x)

108 Veraart JC, Neumann HA, Veraart CJ \& Engelen J. Leg ulcers with hyperpigmented maculae and white atrophy as manifestation of Klinefelter syndrome. Nederlands Tijdschrift voor Geneeskunde 1994 138 86-89.

109 Veraart JC, Hamulyak K \& Neumann HA. Klinefelter's syndrome as a model for skin changes in venous insufficiency. Wiener Medizinische Wochenschrift 1994144 277-278. PubMed id: 7856207.

110 Pernod G, Villemur B, Bosson JL, Truche H, Franco A \& Polack B. Leg ulcers and Klinefelter's syndrome: role of PAI-1. British Journal of Dermatology 1996134 605-606. (doi:10.1111/j.1365-2133.1996. tb16262.x)

111 Dissemond J, Knab J, Lehnen M \& Goos M. Increased activity of factor VIII coagulant associated with venous ulcer in a patient with Klinefelter's syndrome. Journal of the European Academy of Dermatology and Venereology 200519 240-242. (doi:10.1111/ bjd.2005.153.issue-1)

112 Mantle DJ, Pye C, Hardisty RM \& Vessey MP. Plasma factor-VIII concentrations in XXX women. Lancet 1971 1 58-59. (doi:10.1016/ S0140-6736(71)90779-3)

113 Norris PG, Rivers JK, Machin S, Dowd PM \& Griffiths WA. Platelet hyperaggregability in a patient with Klinefelter's syndrome and leg ulcers. British Journal of Dermatology 1987117 107-109. (doi:10.1111/bjd.1987.117.issue-1)

114 Higgins EJ, Tidman MJ, Savidge GF, Beard J \& MacDonald DM. Platelet hyperaggregability in two patients with Klinefelter's syndrome complicated by leg ulcers. British Journal of Dermatology 1989120322

115 Di Minno MN, Esposito D, Di Minno A, Accardo G, Lupoli G, Cittadini A, Giugliano D \& Pasquali D. Increased platelet reactivity in Klinefelter men: something new to consider. Andrology 20153 876-881. (doi:10.1111/andr.2015.3.issue-5)

116 Miller RA, Tremann JA \& Ansell JS. The conservative management of renal vein thrombosis. Journal of Urology $1974111568-571$.

117 Clouse LH \& Comp PC. The regulation of hemostasis: the protein C system. New England Journal of Medicine 1986314 1298-1304.

118 Ranganath LR, Jones L, Lim AG, Gould SR \& Goddard PF. Thrombophilia in a man with long-standing hypogonadism. Postgraduate Medical Journal 199773 761-763. (doi:10.1136/ pgmj.73.865.761)

119 Mount GR \& Roebuck JD. Antiphospholipid syndrome in a 21-yearold with Klinefelter syndrome. Journal of Clinical Rheumatology 2009 15 27-28. (doi:10.4300/JGME-D-13-00365.1)

120 Boos CJ \& Matfin G. Klinefelter's syndrome manifesting as an acute pulmonary embolus in a 52-year-old man. Endocrine Practice 20028 68-69.

121 Igawa K \& Nishioka K. Leg ulcer in Klinefelter's syndrome. Journal of the European Academy of Dermatology and Venereology 200317 62-64.

122 De Morentin HM, Dodiuk-Gad RP \& Brenner S. Klinefelter's syndrome presenting with leg ulcers. Skinmed 20043 274-278. (doi:10.1111/jdv.2006.20.issue-4)

123 Goto Y, Uhara H, Murata H, Koga H, Kosho T, Yamazaki M, Takata M \& Okuyama R. Leg ulcers associated with positive lupus anticoagulant in two cases of Klinefelter's syndrome. Acta DermatoVenereologica 201191 90-91. (doi:10.2340/00015555-0957)

124 Ramaker J, Goerdt S, Zouboulis CC, Schramm W \& Orfanos CE. Recurrent thrombophlebitis and ulcera crurum as manifestations of hereditary blood coagulation disorders and Klinefelter syndrome. Discussion based on 4 case examples. Hautarzt 199748 634-639. (doi:10.1007/s001050050636)

125 Depaire-Duclos F, Gris JC, Dandurand M \& Guillot B. Thrombotic Klinefelter syndrome associated with factor V Leiden mutation. Archives of Dermatology 1997133 1051-1052. (doi:10.1001/ archderm.1997.03890440135027)
126 Lapecorella M, Marino R, De Pergola G, Scaraggi FA, Speciale V \& De Mitrio V. Severe venous thromboembolism in a young man with Klinefelter's syndrome and heterozygosis for both G20210A prothrombin and factor V Leiden mutations. Blood Coagulation \& Fibrinolysis 200314 95-98. (doi:10.1097/00001721-20030100000017)

127 Ayli M \& Ertek S. Serious venous thromboembolism, heterozygous factor V Leiden and prothrombin G20210A mutations in a patient with Klinefelter syndrome and type 2 diabetes. Internal Medicine 200948 1681-1685.

128 Caron P, Bennet A, Camare R, Louvet JP, Boneu B \& Sie P. Plasminogen activator inhibitor in plasma is related to testosterone in men. Metabolism 198938 1010-1015. (doi:10.1016/00260495(89)90014-0)

129 De Pergola G, De Mitrio V, Sciaraffia M, Pannacciulli N, Minenna A, Giorgino F, Petronelli M, Laudadio E \& Giorgino R. Lower androgenicity is associated with higher plasma levels of prothrombotic factors irrespective of age, obesity, body fat distribution, and related metabolic parameters in men. Metabolism 199746 1287-1293.

130 Bennett SA \& Birnboim HC. Receptor-mediated and protein kinasedependent growth enhancement of primary human fibroblasts by platelet activating factor. Molecular Carcinogenesis 199720 366-375.

131 Winkler UH. Hormone replacement therapy and hemostasis: principles of a complex interaction. Maturitas 199624 131-145. (doi:10.1016/S0378-5122(96)82003-2)

132 Winkler UH. Effects of androgens on haemostasis. Maturitas 199624 147-155. (doi:10.1016/S0378-5122(96)82004-4)

133 Arcopinto M, Cella CA, Wesolowski R, Salzano A, Bossone E, Cittadini A \& Baliga RR. Primary prevention of cancer-related thrombosis: special focus on ambulatory patients. International Journal of Cardiology 2014173 583-584. (doi:10.1016/j. ijcard.2014.03.109)

134 Marra AM, Arcopinto M, Bobbio E, Salzano A, Sacca L \& Cittadini A. An unusual case of dilated cardiomyopathy associated with partial hypopituitarism. Internal and Emergency Medicine 20127 (Supplement 2) S85-S87. (doi:10.1016/j.jchf.2013.04.003)

135 Thukuntla S \& Kumar P. Improvement of venous leg ulcers with androgen replacement therapy in a patient with undiagnosed klinefelter syndrome. Dermato-endocrinology 20113 233-234. (doi:10.1210/jc.2011-3252)

136 Ozbek M, Ozturk MA, Ureten K, Ceneli O, Erdogan M \& Haznedaroglu IC. Severe arterial thrombophilia associated with a homozygous MTHFR gene mutation (A1298C) in a young man with Klinefelter syndrome. Clinical and Applied Thrombosis/Hemostasis 200814 369-371. (doi:10.1177/1076029607304750)

137 Kovac J, Pastuszak AW, Lamb DJ \& Lipshultz LI. Testosterone supplementation therapy in the treatment of patients with metabolic syndrome. Postgraduate Medicine 2014126 149-156. (doi:10.3810/pgm.2014.11.2843)

138 Ferlin A, Schipilliti M \& Foresta C. Bone density and risk of osteoporosis in Klinefelter syndrome. Acta Paediatrica 2011100 878-884. (doi:10.2337/dc11-0070)

139 Bojesen A, Hertz JM \& Gravholt CH. Genotype and phenotype in Klinefelter syndrome - impact of androgen receptor polymorphism and skewed X inactivation. International Journal of Andrology 201134 e642-e648. (doi:10.1016/j.nicl.2016.01.005)

140 Rosano GM, Leonardo F, Pagnotta P, Pelliccia F, Panina G, Cerquetani E, della Monica PL, Bonfigli B, Volpe M \& Chierchia SL. Acute anti-ischemic effect of testosterone in men with coronary artery disease. Circulation 199999 1666-1670.

141 Rosano GM, Sheiban I, Massaro R, Pagnotta P, Marazzi G, Vitale C, Mercuro G, Volterrani M, Aversa A \& Fini M. Low testosterone levels are associated with coronary artery disease in male patients with angina. International Journal of Impotence Research 200719 176-182. 
142 Arcopinto M, Salzano A, Isgaard J \& Cittadini A. Hormone replacement therapy in heart failure. Current Opinion in Cardiology 201530 277-284. (doi:10.1097/HCO.0000000000000166)

143 Arcopinto M, Salzano A, Bossone E, Ferrara F, Bobbio E, Sirico D, Vriz O, De Vincentiis C, Matarazzo M, Saldamarco L et al. Multiple hormone deficiencies in chronic heart failure. International Journal of Cardiology 2015184 421-423. (doi:10.1016/j.ijcard.2015.02.055)

144 Marra AM, Improda N, Capalbo D, Salzano A, Arcopinto M, De Paulis A, Alessio M, Lenzi A, Isidori AM, Cittadini A et al. Cardiovascular abnormalities and impaired exercise performance in adolescents with congenital adrenal hyperplasia. Journal of Clinical Endocrinology \& Metabolism 2015100 644-652. (doi:10.1210/jc.20141805)

145 Bojesen A \& Gravholt CH. Klinefelter syndrome in clinical practice. Nature Clinical Practice Urology 20074 192-204. (doi:10.1186/s13567016-0320-6)

146 Radicioni AF, Ferlin A, Balercia G, Pasquali D, Vignozzi L, Maggi M, Foresta C \& Lenzi A. Consensus statement on diagnosis and clinical management of Klinefelter syndrome. Journal of Endocrinological Investigation 201033 839-850. (doi:10.1007/BF03350351)

147 Groth KA, Skakkebaek A, Host C, Gravholt CH \& Bojesen A. Clinical review: Klinefelter syndrome - a clinical update. Journal of Clinical Endocrinology \& Metabolism 201398 20-30. (doi:10.1530/EC-130067)
148 Gies I, Unuane D, Velkeniers B \& De Schepper J. Management of Klinefelter syndrome during transition. European Journal of Endocrinology 2014171 R67-77. (doi:10.1530/EJE-14-0213)

149 Nieschlag E, Werler S, Wistuba J \& Zitzmann M. New approaches to the Klinefelter syndrome. Annales $d$ Endocrinologie (Paris) 201475 88-97. (doi:10.1016/j.ando.2014.03.007)

150 Perk J, De Backer G, Gohlke H, Graham I, Reiner Z, Verschuren M, Albus C, Benlian P, Boysen G, Cifkova R et al. European guidelines on cardiovascular disease prevention in clinical practice (version 2012). The Fifth Joint Task Force of the European Society of Cardiology and Other Societies on cardiovascular disease prevention in clinical practice (constituted by representatives of nine societies and by invited experts). Developed with the special contribution of the European Association for Cardiovascular Prevention \& Rehabilitation (EACPR). European Heart Journal 201233 1635-1701.

151 Zannad F, Dallongeville J, Macfadyen RJ, Ruilope LM, Wilhelmsen L, De Backer G, Graham I, Lorenz M, Mancia G, Morrow DA et al. Prevention of cardiovascular disease guided by total risk estimations - challenges and opportunities for practical implementation: highlights of a CardioVascular Clinical Trialists (CVCT) workshop of the ESC Working Group on cardioVascular pharmacology and drug therapy. European Journal of Cardiovascular Prevention and Rehabilitation 201219 241-249. (doi:10.1177/1741826710394305)

Received 17 October 2015

Revised version received 22 January 2016

Accepted 4 February 2016 